\title{
Pectic and Galacturonic Acid Oligosaccharides on the Postharvest Performance of Citrus Fruits
}

\author{
Araceli M. Vera-Guzman ${ }^{1}$ \\ Centro de Investigación en Alimentación y Desarrollo, A. C. (CIAD), Centro \\ Público de Investigación del Consejo Nacional de Ciencia y Tecnología \\ (CONACyT), Carretera a la Victoria Km 0.6, Hermosillo, 83304, Sonora, \\ México; and Instituto Politécnico Nacional, CIIDIR Unidad Oaxaca, Hornos \\ No. 1003, Santa Cruz Xoxocotlán, 71230, Oaxaca, México
}

\section{Maria T. Lafuente \\ Instituto de Agroquímica y Tecnología de Alimentos (IATA). Consejo Superior de Investigaciones Cientificas (CSIC), Avenida Agustín Escardino 7, Paterna, 46980, Valencia, Spain}

\section{Emmanuel Aispuro-Hernandez, Irasema Vargas-Arispuro, and Miguel A. Martinez-Tellez ${ }^{2}$}

Centro de Investigación en Alimentación y Desarrollo, A. C. (CIAD), Centro Público de Investigación del Consejo Nacional de Ciencia y Tecnología (CONACyT), Carretera a la Victoria Km 0.6, Hermosillo, 83304, Sonora, México

Additional index words. orange, grapefruit, cold storage, chilling injury, nonchilling peel pitting, decay

Abstract. Orange [Citrus sinensis (L.) Osbeck] and grapefruit (Citrus paradisi Macfad) citrus fruits are prone to develop different peel physiological disorders caused by storage at both chilling and nonchilling temperatures. The effect of galacturonic acid oligosaccharides (GAOs) and pectic oligosaccharides (POs) in reducing postharvest nonchilling peel pitting (NCPP), decay, and chilling injury (CI) in orange cv. Navelina and the effect of POs in reducing CI in grapefruit cv. Rio Red, were investigated. The incidence of these disorders was examined in fruits stored at chilling and nonchilling temperatures and at $90 \%$ to $95 \%$ relative humidity (RH). POs showed a better efficacy than GAOs in reducing postharvest losses in orange. The POs were able to reduce NCPP and decay in 'Navelina' fruits stored at $20{ }^{\circ} \mathrm{C}$, irrespective of the fruit maturity stage. The application of $10 \mathrm{~g} \cdot \mathrm{L}^{-1} \mathrm{POs}$ also reduced $\mathrm{CI}$ and the chilling-induced ethylene production in oranges and grapefruits maintained at the chilling temperature. Likewise, the decrease in ethylene production found in 'Navelina' fruits that developed NCPP during storage at the nonchilling temperature was related to lower peel damage. Moreover, results showed that POs do not induce an increase in ethylene when fruit are stored under conditions that do not cause stress-related injury to fruit. Therefore, POs efficacy in reducing postharvest physiological disorders is not likely mediated by ethylene. Overall results indicate that the application of POs may be an acceptable alternative to mitigate postharvest losses of citrus fruits.

Citrus are the first fruit crop in international trade in terms of economic value (FAOSTAT, 2014). Citrus grow not only in

\footnotetext{
Received for publication 18 Oct. 2016. Accepted for publication 29 Nov. 2016.

Part of this work was supported by the Spanish Ministry of Science and Technology (research grant AGL2013-41734-R and AGL2014-55802-R) and by the Generalitat Valenciana, Spain (grant PROMETEOII/2014/027).

We also thank Francisco J Soto Cordova, Cynthia L Aguilar Gil and Demetrio Morales Flores for technical support.

${ }^{1}$ Araceli M. Vera-Guzman is a doctoral student in the graduate program of CIAD, and received a graduate fellowship from CONACyT, México.

${ }^{2}$ Corresponding author. E-mail: norawa@ciad.mx.
}

areas with Mediterranean-type climates but also in areas with tropical and subtropical climates; often facing severe abiotic and biotic stresses. Important economic losses occur during postharvest handling and storage of this horticultural crop due to such stresses, which may end in fruit quality loss or in decay caused by pathogenic fungi. Peel blemishes or physiological peel disorders are key factors affecting external fruit quality for fresh consumption. Different postharvest peel disorders have been described in citrus fruit. However, the responsible causes for many of them are not well understood, their incidence being erratic, and showing high variability among orchards and from year to year (Lafuente and Zacarías, 2006). Likewise, the susceptibility of citrus fruit to postharvest physiological disorders may depend on the cultivar, the fruit maturity stage, and also on preharvest weather conditions (Gonzalez-Aguilar et al., 2000; Lafuente and Zacarías, 2006; Martínez-Téllez and Lafuente, 1997). NCPP, also known as rind staining, and CI are two main postharvest disorders in citrus fruit (Lafuente and Zacarías, 2006). CI develops during fruit storage at temperatures ranging between 1 and $12{ }^{\circ} \mathrm{C}$, depending on the citrus cultivar, whereas NCPP develops at higher temperatures. Sweet oranges from the Navel group are prone to develop NCPP, whereas grapefruit is very susceptible to CI (Lafuente and Zacarías, 2006; Mulas and Schirra, 2007). In grapefruits, $\mathrm{CI}$ is manifested as small brown pitting on the flavedo (outer colored part of the peel) (Fig. 1), which increases in size and number with prolonged storage time (Lado et al., 2015). However, CI may be also manifested as superficial scalding or flavedo bronze nondepressed areas in other citrus cultivars (Lafuente and Zacarías, 2006; Mulas and Schirra, 2007). NCPP manifests as irregular colorless depressed areas on the peel affecting both the inner part of the peel (albedo) and the flavedo that increase in number and extension and may turn brown over time (Alférez et al., 2003; Lafuente and Sala, 2002; Lafuente et al., 2014).

Efforts have focused on determining the causes of different physiological disorders in citrus fruit and developing new methods to control them. However, no proven strategy currently exists to reduce their incidence. Most studies have been related to methodologies aiming at reducing CI, whose effect on citrus fruit quality has been well characterized (Mulas and Schirra, 2007; Schirra et al., 2004; Schirra and Mulas, 1995). Conditioning mature citrus fruit with ethylene has been shown to be effective in reducing NCPP in fruit harvested through different citrus seasons (Cajuste et al., 2010; Lafuente and Sala, 2002; Lafuente, et al., 2014; Vicente et al., 2013). However, the mode of action of ethylene increasing the tolerance of citrus fruit to NCPP and also the mechanisms involved in the development of this physiological disorder are still poorly understood. Citrus fruits produce small amounts of ethylene although the production of this plant hormone increases markedly in citrus fruits in response to chilling (Martínez-Téllez and Lafuente, 1997) or to conditions favoring the development of NCPP (Alférez et al., 2003). In the context of the present work, it is also noticeable that ethylene, besides of reducing NCPP, plays a protective role against CI (Lafuente et al., 2001) and pathogens invasion in citrus fruit (Cajuste et al., 2010).

Previous investigations indicate that the ethylene-induced modifications in cell wall might participate in the beneficial effect of the hormone reducing NCPP in citrus fruits (Cajuste et al., 2011) and it has encouraged understanding whether ethylene-induced cell wall-derived oligomers (OGs) may play a role reducing the disorder (Vicente et al., 2013). 


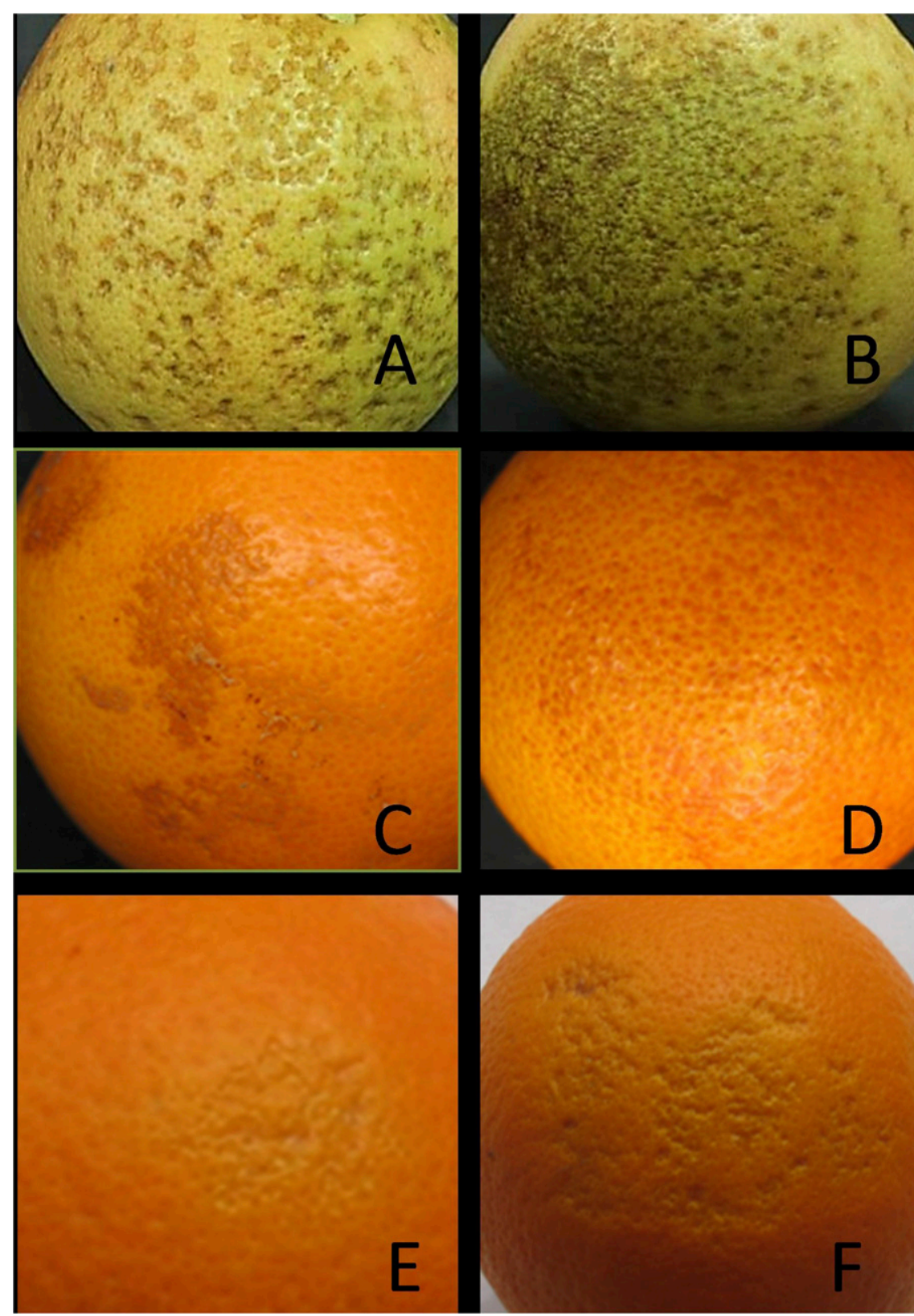

Fig. 1. Symptoms of chilling injury in (A, B) 'Rio Red' grapefruits and $(\mathbf{C}, \mathbf{D})$ 'Navelina' oranges stored at $2{ }^{\circ} \mathrm{C}$ and symptoms of nonchilling peel pitting in $(\mathbf{E}, \mathbf{F})$ 'Navelina' oranges stored at $20^{\circ} \mathrm{C}$ and $90 \%$ to $95 \%$ relative humidity.

OGs are carbohydrate fragments resulting from the hydrolysis of the main cell wall polymers cellulose, hemicellulose, and pectin (Ochoa-Villarreal et al., 2012). A role for pectic substances in the acclimation of other fruits to low temperature stress causing peel collapse has been also suggested (BalandránQuintana et al., 2002), although the involvement of OGs in the tolerance of citrus fruit to chilling remains unknown. The perception of the cell wall as a solely rigid structure providing mechanical support is long past. Now, it is accepted that it has a key role in a plant's interactions with responses to abiotic stresses and pathogens (Sasidharan et al., 2011). Dynamic modifications in wall polymers occur in response to environmental conditions and hormones like ethylene, and wall postharvest physiological disorders and decay. Therefore, the aim of this study has been to evaluate the effect of OGs on the incidence of postharvest NCPP, CI, and decay, which are caused by different environmental factors in citrus fruit, with and whether these effects can be mediated by ethylene.

\section{Materials and Methods}

Fruit material. Fruits from full mature 'Navelina' sweet orange (C. sinensis) were harvested after color break, color a:b of 0.36 and 0.72 , and with maturity index of 6.9 and 9.4 in December and January, respectively, from the same orchard at Lliria (Valencia, Spain), which has a Mediterranean climate. During these months the average temperatures ranged between 12 and $15^{\circ} \mathrm{C}$. 'Rio Red' grapefruits $(C$. paradisi) were harvested at the beginning of November at the breaker maturity stage, color a:b of -0.066 , and maturity index of 5.9 from adult trees in an experimental orchard located in La Costa of Hermosillo, Sonora, Mexico, which is a hot desert region whose annual average temperature in November is around $21{ }^{\circ} \mathrm{C}$. Fruit from all cultivars were immediately delivered to the laboratory after harvest. They were visually inspected to be free of damage and defects, selected on the basis of uniform size, randomized, washed, disinfected with a sodium hypochlorite solution (Ballester and Lafuente, 2017) and rinsed with tap water before being allowed to air-dry at room temperature.

Preparation of cell wall derived OGs. The POs and the GAOs mixtures with a degree of polymerization (DP) from 3 to 20 were respectively obtained by enzymatic hydrolysis of either low methoxyl pectin (Grindsted $^{\circledR}$ LC-950; Danisco Mexicana, Colima, México) or polygalacturonic acid (Sigma-Aldrich, St. Louis, MO) using a pectinase from Aspergillus niger (Sigma) for $15 \mathrm{~min}$ at $23{ }^{\circ} \mathrm{C}$. The POs mixture also included $0.94 \%$ arabinose, $0.18 \%$ galactose, and $1.1 \%$ glucose. Aliquots were analyzed by high-performance anion exchange chromatography with pulsed amperometric detection (Dionex, Sunnyvale, CA). The DP was calculated according to the trigalacturonic acid standard from sigma (Ochoa-Villarreal et al., 2011) and the total carbohydrates content was analyzed according to the ISO 11292 method (1995).

Treatments and storage conditions. The disinfected fruits were divided into different groups, each containing three replicates of 23 fruits, which were exposed to different treatments and/or temperatures. All the treatments were performed in triplicate. The first experiment was performed using 'Navelina' sweet oranges harvested in December. This cultivar was selected because it is very prone to develop NCPP. Three groups containing three replicates with the same number of fruits were prepared. One group was treated with $2.5 \mathrm{~g} \cdot \mathrm{L}^{-1}$ of POs $(\mathrm{pH} ; 5.5)$, one with $2.5 \mathrm{~g} \cdot \mathrm{L}^{-1}$ of GAOs $(\mathrm{pH} ; 5.5)$, and the third group was used as control and treated with water. All fruit in this experiment were stored 


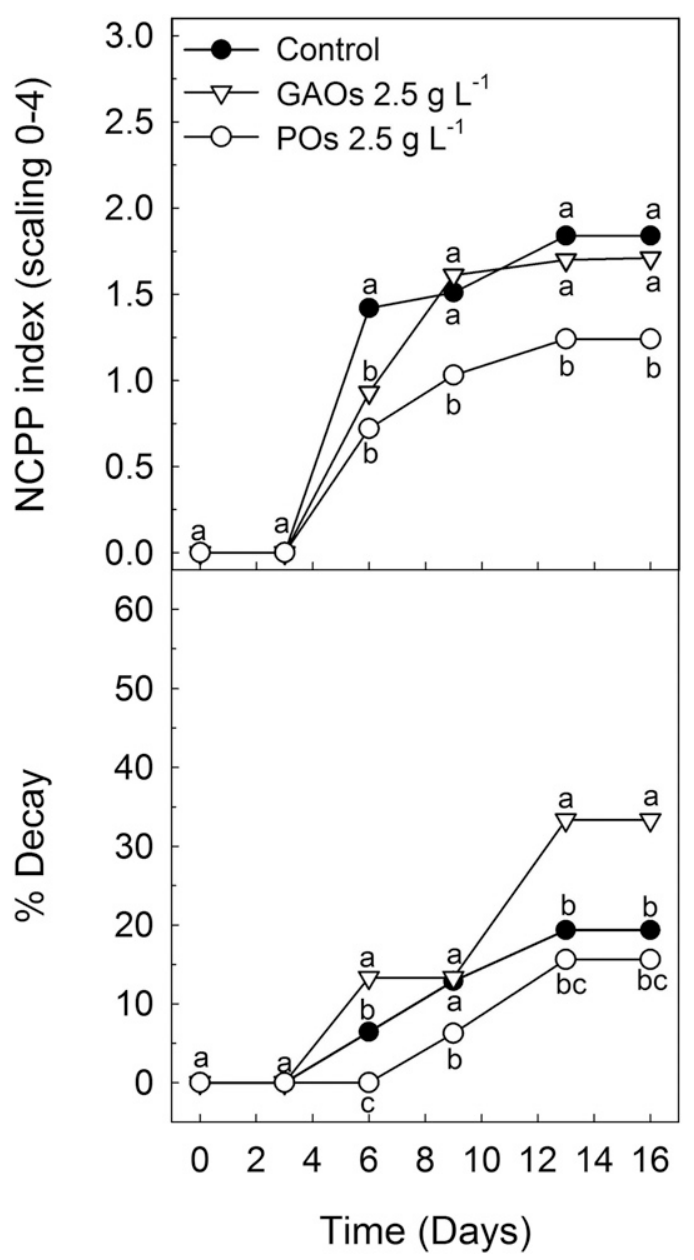

Fig. 2. Effect of treating 'Navelina' oranges harvested in December with $2.5 \mathrm{~g} \cdot \mathrm{L}^{-1}$ pectic oligosaccharides (POs) or galacturonic acid oligosaccharides (GAOs) on nonchilling peel pitting (NCPP) index and on decay incidence of fruit stored at $20^{\circ} \mathrm{C}$. Different letters indicate significant differences $(P<0.05)$ among treatments for the same storage period.

for $16 \mathrm{~d}$ at $20{ }^{\circ} \mathrm{C}$ and $90 \%$ to $95 \% \mathrm{RH}$ to determine the effect of both oligosaccharides on NCPP and the incidence of natural decay caused by pathogenic fungi.

On the basis of results obtained in the first experiment, the effects of $10 \mathrm{~g} \cdot \mathrm{L}^{-1}$ of POs $(\mathrm{pH} ; 5.5)$ on decay, external quality, and on the physiology of 'Navelina' fruits were evaluated in a second experiment. The effect of applying $10 \mathrm{~g} \cdot \mathrm{L}^{-1}$ of POs in fruit of the same cultivar (Navelina) harvested in January was studied during a 45-d storage period at $20^{\circ} \mathrm{C}$, which causes NCPP, and at $2{ }^{\circ} \mathrm{C}$ that may induce CI. Thus, six groups of fruit were prepared in this experiment; three groups were stored at $20{ }^{\circ} \mathrm{C}$, and three at $2{ }^{\circ} \mathrm{C}$. Considering the high susceptibility of grapefruit to CI, we further examined in a third experiment the effect of applying 2.5 and 10 g. $\mathrm{L}^{-1}$ of POs in 'Rio Red' grapefruit cultivar, which was stored for $42 \mathrm{~d}$ at $2{ }^{\circ} \mathrm{C}$ (chilling temperature) and at $13{ }^{\circ} \mathrm{C}$ (control nonchilling temperature that delays fruit senescence). Therefore, fruit were divided in six independent groups containing the same number of fruit, three groups for fruit stored at $2{ }^{\circ} \mathrm{C}$ and three that were stored at $13{ }^{\circ} \mathrm{C}$. By this approach we checked the effect of POs on two different citrus cultivars at different maturity stages and subjected to different preharvest conditions, which may influence the susceptibility of citrus fruit to develop postharvest physiological disorders (Dou et al., 2005; Lafuente and Zacarías, 2006; Ritenour et al., 2003). All treatments were applied by spraying each fruit with either distilled water or OGs solutions.

The effects of the OGs on external fruit quality, as determined by the incidence of CI and NCPP, on the natural decay development (noninoculated fruits), and on the fruit physiology were evaluated every $7 \mathrm{~d}$ during storage. A total of 20 fruit per replicate were used to assess physiological disorders; in each sampling date three fruit were used per replicate to evaluate ethylene production.

Fruit color and maturity index. Fruit color and the maturity index were analyzed as previously reported by Lafuente et al. (2014). Color was measured by using a Minolta CR300 Chromameter (Konica Minolta Inc., Tokyo, Japan) at four locations around the equatorial plane of the fruit and expressed as the $a: b$ ratio that is classically used for color measurement in citrus fruit (Stewart and Wheaton, 1972). This ratio is negative for green fruit and positive for orange fruit, whereas zero value corresponds to yellow fruit at the midpoint of color break period. The maturity index was assessed by dividing the soluble solids contents (Brix) of the pulp by its acids content. Acids content was titrated with $0.1 \mathrm{~N} \mathrm{NaOH}$ using phenolphthalein as indicator, with a $\mathrm{pH}$ at endpoint in a range of 8.25 to 8.34 . Results were expressed as $g$ of anhydrous citric acid in 100 $\mathrm{mL}$ of juice.

Estimation of postharvest physiological disorders severity and incidence. Since NCPP and CI symptoms were different (Fig. 1), the severity and/or incidence of these physiological disorders were evaluated independently during fruit storage at the different temperatures selected in the present study. NCPP, occurring in 'Navelina' oranges at $20{ }^{\circ} \mathrm{C}$, manifested as collapsed surface areas that affected to the albedo and the flavedo, which may become dark brown in fruit showing severe damage. CI occurred both in oranges and grapefruit fruit at $2{ }^{\circ} \mathrm{C}$. In oranges, CI manifested as bronzed nondepressed areas (scalding) of the fruit surface, whereas in grapefruit brown, pit-like depressions on the fruit surface was the main CI symptom. A rating scale from 0 (no damage) to 4 (severe damage) was used to determine $\mathrm{CI}$ and NCPP indexes as previously described (Lafuente et al., 2014). The same fruit were used at the various evaluations dates. The severity indexes were calculated by adding up the products of the number of fruit in each category multiplied by its score, and then dividing the total obtained by the number of fruit evaluated. The incidence of each disorder and of decay was determined by calculating the percent of fruit showing damage or rots. The results are the means of three replicate samples of 20 fruits each \pm SE.

Sensory evaluation. Sensory evaluation was performed by eight-semitrained panellists using a rating scale from 1 to 10 , where 10 = excellent flavor and $1=$ extremely unpleasant (Sdiri et al., 2012).

Ethylene production. Ethylene production from whole fruits of each citrus cultivar was measured periodically during storage. At least three fruit per replicate were incubated in sealed glass containers. Orange fruit were incubated at the corresponding storage temperature. In grapefruits, ethylene production of the fruits stored at low temperature was determined in fruits incubated at $20{ }^{\circ} \mathrm{C}$ to magnify the effect of chilling. After $4 \mathrm{~h}$ of incubation, a 1-mL gas sample was withdrawn from the headspace of the container and injected into a gas chromatograph equipped with a HayeSep N column ( 2 m, 1/8 inch ID) and a flame ionization detector. The temperatures of the injector and of detector were held at $100{ }^{\circ} \mathrm{C}$ and $120^{\circ} \mathrm{C}$, respectively. Nitrogen was used as a carrier gas, and the temperature of the column was maintained at $80{ }^{\circ} \mathrm{C}$. Ethylene concentrations were determined by comparison with standards. The results are the mean of three replicates and are expressed on a fresh weight basis as $\mathrm{nL} \mathrm{C}_{2} \mathrm{H}_{4} \cdot \mathrm{g}^{-1} \cdot \mathrm{h}^{-1}$. 


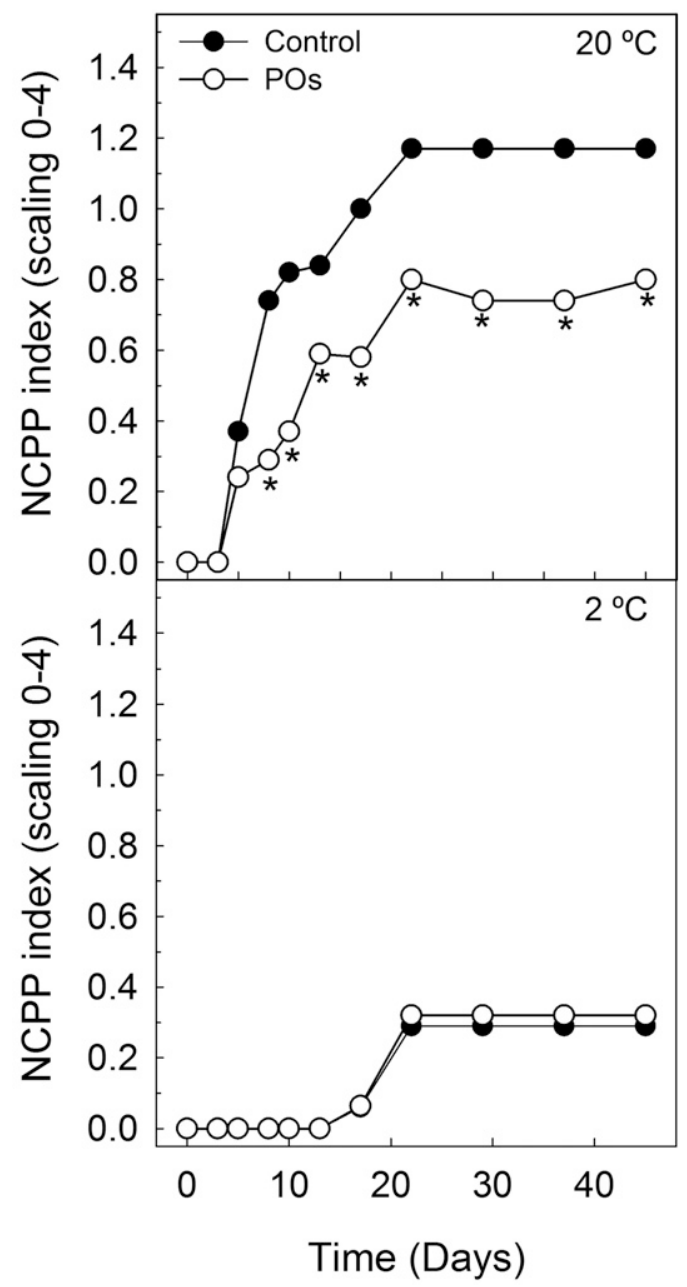

Fig. 3. Effect of treating 'Navelina' oranges harvested in January with $10 \mathrm{~g} \cdot \mathrm{L}^{-1}$ POs on nonchilling peel pitting (NCPP) index of fruit stored at 20 and $2{ }^{\circ} \mathrm{C}$. Asterisks indicate significant differences $(P<0.05)$ between POs and their respective control samples for the same storage period.

Statistical analysis. The data were subjected to analysis of variance using SAS software (Statistical Analysis System Institute, Cary, NC). A mean comparison using Tukey's test $(P<0.05)$ was performed to determine differences between treatments and storage conditions on NCPP index, \% decay, \% CI, and ethylene production.

\section{Results}

As indicated in the introduction, OGs play defensive roles in plants against biotic and abiotic stresses that promote injury and decay. However, their involvement in the susceptibility of citrus fruit to develop NCPP, $\mathrm{CI}$, or decay remains unknown. In the present work, we have first examined the effect of two types of OGs; POs and GAOs applied at the same concentration, on the susceptibility of 'Navelina' oranges to develop NCPP and fruit decay when the fruit were stored at a nonchilling temperature. Results showed that the GAOs initially reduced the development of NCPP, but its efficacy was lost by day 8. However, GAOs promoted decay (Fig. 2). In contrast, POs significantly reduced NCPP along the whole storage period and decay for up to $9 \mathrm{~d}$. Thereafter, decay was still lower in the POs-treated fruits although differences were not statistically significant. Considering these results, the POs treatment was selected for subsequent experiments.

On the basis of the results obtained in the first experiment, we increased the POs concentration from 2.5 to $10 \mathrm{~g} \cdot \mathrm{L}^{-1}$ and also examined the effect of POs for longer storage periods on NCPP in 'Navelina' fruit stored at $20{ }^{\circ} \mathrm{C}$, which favor the development of this disorder; and at $2{ }^{\circ} \mathrm{C}$ since refrigerated storage is required to extend fruit storage life. Results showed that the efficacy of the POs decreasing NCPP persisted for up to $40 \mathrm{~d}$ for fruit kept at $20{ }^{\circ} \mathrm{C}$ (Fig. 3). The incidence of NCPP at $2{ }^{\circ} \mathrm{C}$ was very low. By day 40 the NCPP index was $\approx 0.3$ at this temperature where the rating scale ranged from 0 to 4 , whereas an index of 1 makes the fruit unmarketable. No effect of the POs on NCPP severity was observed at $2{ }^{\circ} \mathrm{C}$. No decay occurred at $2{ }^{\circ} \mathrm{C}$ either in the control or the POs-treated fruit (data not shown). As shown in Fig. 4, the incidence of decay was reduced at $20^{\circ} \mathrm{C}$ when the fruit were treated with the POs. Furthermore, the POs reduced the percent of fruits showing $\mathrm{CI}$ in 'Navelina' fruits stored at $2{ }^{\circ} \mathrm{C}$. The efficacy of applying $10 \mathrm{~g} \cdot \mathrm{L}^{-1}$ on reducing CI was further confirmed in 'Rio Red' grapefruits held at $2{ }^{\circ} \mathrm{C}$ (Fig. 5). At this concentration, the POs significantly reduced the incidence of the disorder till the end of the storage period. Fruit treated with 2.5 g. $\mathrm{L}^{-1}$ had no difference in CI. On the other hand, a very low percent of grapefruit stored at $13{ }^{\circ} \mathrm{C}$ developed $\mathrm{CI}$ and the severity of injury was negligible. By day 42 , they showed a CI index of $\approx 0.3$, in a rating scale from 0 to 4 , and no differences were found between control and POs-treated fruits. Along with these external quality attributes, a sensory evaluation was performed and no relevant difference between the control and the treated fruit was detected (data not shown). Similarly, POs had no relevant effect on fruit color (data not shown).

The OGs may increase ethylene production in different crops but its effect on the hormone production in citrus fruits its unknown. Ethylene production transiently increased in 'Navelina' fruits held at $20^{\circ} \mathrm{C}$ and showed little changes in fruits stored at $2{ }^{\circ} \mathrm{C}$ (Fig. 6). The maximum ethylene production was observed by day 24 , when visible injury was evident in fruit held at $20{ }^{\circ} \mathrm{C}$. By this period fruit reached a NCPP index of $\approx 1$, which is indicative of slight but observable injury. POs did not increase ethylene production, compared with the controls, at this temperature. In fact, the transient increase in the hormone production was significantly lower in the POs-treated samples, which showed lower NCPP at $20^{\circ} \mathrm{C}$. The severity of injury in 'Navelina' fruit stored at $2{ }^{\circ} \mathrm{C}$ was very low by day $21(\approx 0.8$ and 0.5 , in a rating scale from 0 to 4 , in the control and the POstreated fruits, respectively). Therefore, little CI-induced ethylene production was observed either in the control or the POstreated samples. Only by $42 \mathrm{~d}$ ethylene did increase and the increase was also lower in the samples treated with POs, which showed lower CI [CI of $\approx 0.9$ (POs treated) and 1.5 (control)] (Fig. 6).

Ethylene production of grapefruit stored at $13{ }^{\circ} \mathrm{C}$ was very low as compared with that of fruit stored at the chilling temperature $\left(2{ }^{\circ} \mathrm{C}\right)$. By day 42 , ethylene increased and POs-treated fruits showed significant lower production than the control fruits (Fig. 7). Although ethylene production of POs-treated fruits was higher than that of control samples by day 28 in grapefruit stored at $2{ }^{\circ} \mathrm{C}$, after $30 \mathrm{~d}$ the fruits treated with POs produced much less ethylene (Fig. 7), and this occurred when differences in CI was very evident (Fig. 5).

\section{Discussion}

OGs have been related to a number of signal transduction pathways involved in growth (Hernández-Mata et al., 2010), and development and defense responses (Ferrari et al., 2013) of higher plants. In this study, we found that the efficacy of the POs and GAOs in reducing decay and NCPP development in 'Navelina' oranges was different. Such 


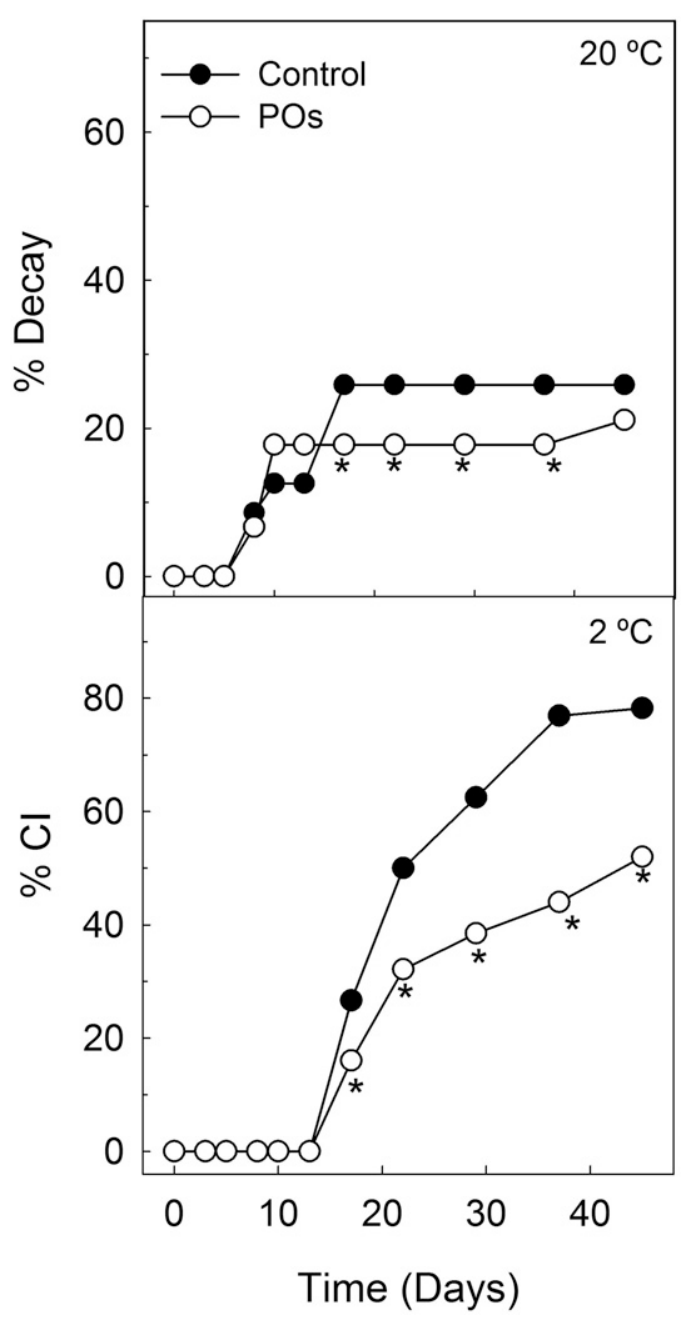

Fig. 4. Effect of treating 'Navelina' oranges with $10 \mathrm{~g} \cdot \mathrm{L}^{-1} \mathrm{POs}$ on the incidence of natural decay in fruit stored at $20^{\circ} \mathrm{C}$ and on the incidence of chilling injury (CI) in fruits stored at $2{ }^{\circ} \mathrm{C}$. Asterisks indicate significant differences $(P<0.05)$ between POs and their respective control samples for the same storage period.

difference could be related to variations between the oligosaccharides properties, such as the chemical composition and the structure of hydrolyzed fragments. GAOs are lineal OGs of galacturonic acid, whereas POs are a mixture of pectic OGs that besides the galacturonic acid core may include different oligomeric carbohydrates like arabinans and galactans which exerts striking differences on the activity and specificity to regulate some physiological processes in plants (Ochoa-Villarreal et al., 2012). OGs concentration, polymerization degree, and structural features determine the kind of biological responses induced at the plant cell surface (Mathieu et al., 1991; Ochoa-Villarreal et al., 2012). In addition, we demonstrated the efficacy of POs reducing CI in two different citrus cultivars and harvested at two different maturity stages, which is in concordance with results suggesting that POs may act as early defense signals for protecting tissues against chilling in zucchini squash (BalandránQuintana et al., 2002). We also found that POs were effective in reducing NCPP regardless of the orange maturity stage although this factor may have an important effect on the efficacy and on the changes induced by postharvest treatments (Lafuente and Zacarías, 2006).

The mode of action of the OGs in plants is still not fully understood, although a number of biochemical and molecular mechanisms operating at the cell surface and the subsequent signaling events are already known (Larskaya and Gorshkova, 2015). In the context of the present work it is important to mention that OGs are recognized by receptor(s) in the cell wall and plasma membrane, which elicits biological responses via a signal transduction cascade (Ridley et al., 2001). Some of these responses have been related to the susceptibility of citrus fruit to develop postharvest physiological disorders or decay. Thus, the OGs may lead to a massive but transient accumulation of reactive oxygen species, which together with the production of specific signaling molecules, such as ethylene induction of secondary metabolite biosynthetic genes such as phenylalanine ammonia lyase of the phenylpropanoids pathway and other hormones, can contribute to the

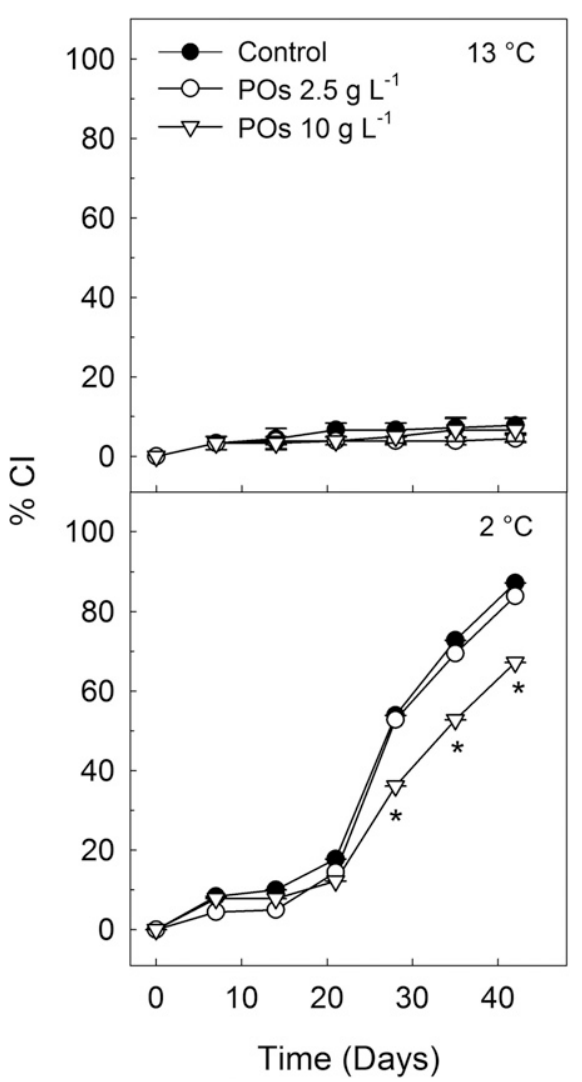

Fig. 5. Effect of treating 'Rio Red' grapefruits with 2.5 and $10 \mathrm{~g} \cdot \mathrm{L}^{-1}$ POs on chilling injury $(\mathrm{CI})$ index of fruit stored at 13 and $2{ }^{\circ} \mathrm{C}$. Asterisks indicate significant differences $(P<0.05)$ between POs and their respective control samples for the same storage period.

(Ochoa-Villarreal et al., 2011, 2012; Ridley et al., 2001; Zhao et al., 2005); as well as of the antioxidant enzymatic system (Camejo et al., 2012). Likewise, it has been shown the relevance of the plasma membrane and oxidative stress in the susceptibility of citrus fruit to develop NCPP (Alférez et al., 2008; Establés-Ortiz et al., 2016; Sala and Lafuente, 2004) as well of the antioxidant enzymatic system for protecting citrus fruit against CI (Sala and Lafuente, 2000) and decay (Ballester at al., 2006). Within the antioxidant system, catalase plays a key role in the induced tolerance against CI in citrus fruit (Sala and Lafuente, 2000), and this enzyme may be induced by OGs (Camejo et al., 2012). In addition, it has been shown that phenylpropanoids play important roles in the defense of citrus fruit against conditions causing CI, NCPP, and postharvest decay (Ballester et al., 2011; Lafuente et al., 2001; Martínez-Téllez and Lafuente, 1997). Results from this research should encourage future work to understand the involvement of phenylpropanoids and the antioxidant system in the beneficial effect of POs reducing postharvest physiological disorders and decay in citrus fruits.

The link between ethylene and the OGsinduced defense response in a different plant system has also been proposed (Larskaya and 


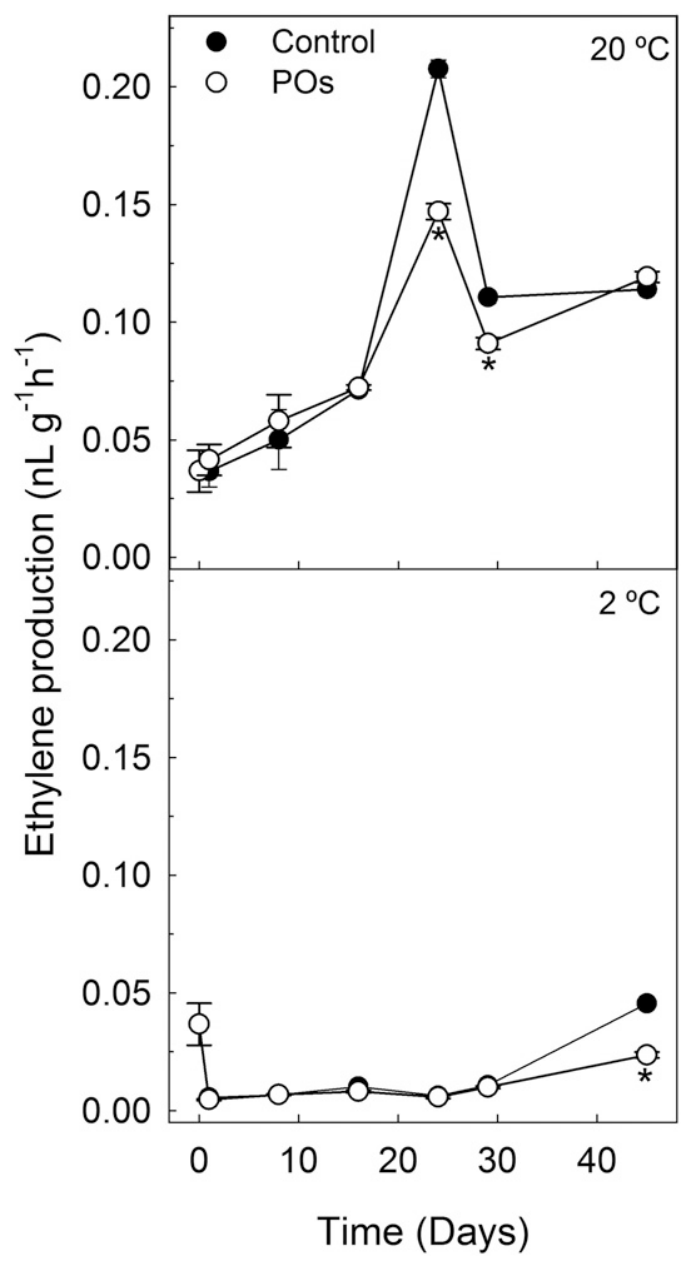

Fig. 6. Effect of treating 'Navelina' oranges with $10 \mathrm{~g} \cdot \mathrm{L}^{-1} \mathrm{POs}$ on ethylene production of fruit stored at 20 and $2{ }^{\circ} \mathrm{C}$. Asterisks indicate significant differences $(P<0.05)$ between POs and their respective control samples for the same storage period.

Gorshkova, 2015; Ma et al., 2016). Ethylene reduces physiological disorders (Lafuente and Sala, 2002; Lafuente et al., 2004; Salvador et al., 2006) and decay (Marcos et al., 2005) in citrus fruit and it has an important effect on inducing relevant changes in the antioxidant system and phenylpropanoid metabolism when applied under conditions favoring NCPP or CI (Cajuste and Lafuente, 2007; Establés-Ortiz et al., 2016; Lafuente et al., 2004; Sala and Lafuente, 2004). Previous results from our group showed that the increase of this hormone is a citrus fruit physiological response to conditions favoring the development of CI (Martínez-Téllez and Lafuente, 1997) and NCPP (Alférez et al., 2005). In this study, we have shown that ethylene transiently increased with the development of NCPP, which is in concordance with previous findings in oranges exposed to water stress favoring the disorder (Alférez et al., 2003), and that such increment was reduced by applying POs (Fig. $6,20^{\circ} \mathrm{C}$ ) at a concentration that reduced the disorder (Fig. 3, $20{ }^{\circ} \mathrm{C}$ ). Similarly, we demonstrated that applying POs reduced $\mathrm{CI}$ and the chilling-induced ethylene production in both oranges and grapefruits. Such increase was associated with peel injury in both CI and
NCPP. Findings of the present work may well indicate that such reduction should be related to the lower NCPP or CI incidence in the POs-treated fruits. The OGs induce ethylene biosynthesis in climacteric tomato fruit (Ma et al., 2016). Results from this work showing that applying POs did not increase, or even reduced, ethylene production when the fruits were stored under conditions that did not induce relevant damage, further suggest that the hormone is not likely mediating the beneficial effects of POs in citrus fruits. Moreover, the specific POs obtained in the present work appear not to be able to induce ethylene in citrus fruit.

In summary, the POs mixture was more effective than that derived from polygalacturonic acid reducing NCPP and decay in citrus fruits, although they were not able to avoid them. POs treatment was able to reduce decay and also postharvest physiological disorders, irrespective of the fruit maturity stage without inducing relevant changes in fruit color or flavor. The effect of POs on ethylene production of citrus fruit was more likely related to the reduction of injury associated with NCPP or CI than to its effect on modifying ethylene biosynthesis. That is, the beneficial effects of POs on the postharvest

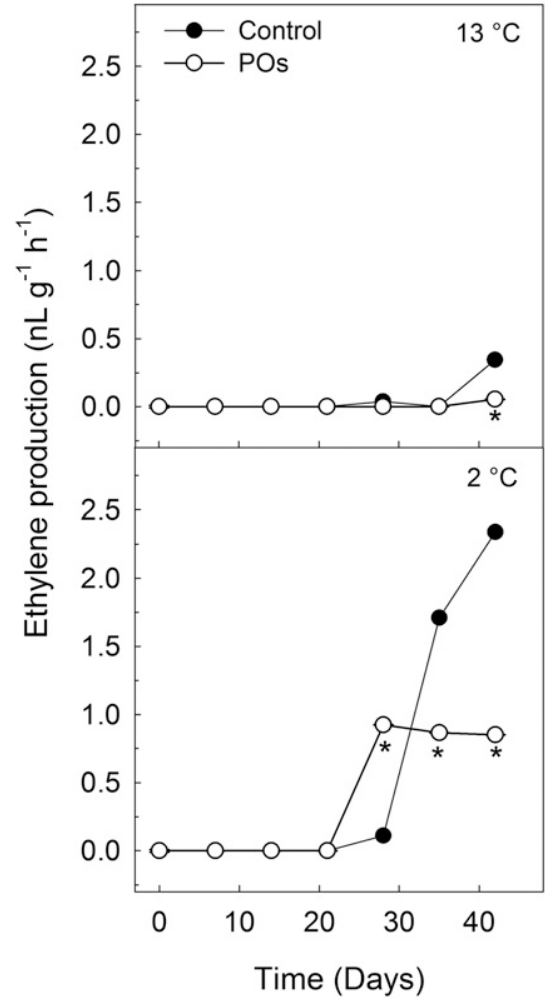

Fig. 7. Effect of treating 'Rio Red' grapefruits with $10 \mathrm{~g} \cdot \mathrm{L}^{-1}$ POs on ethylene production of fruit stored at 13 and $2{ }^{\circ} \mathrm{C}$. Asterisks indicate significant differences $(P<0.05)$ among treatments for the same storage period.

performance of citrus fruit appear not to be mediated by ethylene. Thus, the understanding of the mechanisms induced by POs may help to reduce postharvest losses in citrus fruit.

\section{Literature Cited}

Alférez, F., M. Agusti, and L. Zacarías. 2003. Postharvest rind staining in Navel oranges is aggravated by changes in storage relative humidity: Effect on respiration, ethylene production and water potential. Postharvest Biol. Technol. 28(1):143-152.

Alférez, F., J.M. Sala, M.T. Sanchez-Ballesta, M. Mulas, M.T. Lafuente, and L. Zacarias. 2005. A comparative study of the postharvest performance of an ABA-deficient mutant of oranges: I. Physiological and quality aspects. Postharvest Biol. Technol. 37(3):222-231.

Alférez, F., Y. Lluch, and J.K. Burns. 2008. Phospholipase A 2 and postharvest peel pitting in citrus fruit. Postharvest Biol. Technol. 49(1):6976.

Balandrán-Quintana, R.R., A.M. Mendoza-Wilson, G. Alvarez-Manilla, C.W. Bergmann, I. VargasArispuro, and M.A. Martínez-Téllez. 2002. Effect of pectic oligomers on physiological responses of chilling injury in discs excised from Zucchini (Cucurbita pepo L.). Biochem. Biophys. Res. Commun. 290(1):577-584.

Ballester, A.R. and M.T. Lafuente. 2017. LED blue light-induced changes in phenolics and ethylene in citrus fruit: Implication in elicited resistance against Penicillium digitatum infection. Food Chem. 218:575-583.

Ballester, A.R., M.T. Lafuente, and L. GonzálezCandelas. 2006. Spatial study of antioxidant 
enzymes, peroxidase and phenylalanine ammonia-lyase in the citrus fruit-Penicillium digitatum interaction. Postharvest Biol. Technol. 39(2):115-124.

Ballester, A.R., M.T. Lafuente, J. Forment, J. Gadea, R.C. De Vos, A.G. Bovy, and L. González-Candelas. 2011. Transcriptomic profiling of citrus fruit peel tissues reveals fundamental effects of phenylpropanoids and ethylene on induced resistance. Mol. Plant Pathol. 12 (9):879-897.

Camejo, D., M.C. Martí, E. Olmos, W. Torres, F. Sevilla, and A. Jiménez. 2012. Oligogalacturonides stimulate antioxidant system in alfalfa roots. Biol. Plant. 56(3):537-544.

Cajuste, J.F., F.J. García-Breijo, J. Reig-Armiñana, and M.T. Lafuente. 2011. Ultrastructural and histochemical analysis reveals ethylene-induced responses underlying reduced peel collapse in detached citrus fruit. Microsc. Res. Tech. 74:970-979.

Cajuste, J.F., L. González-Candelas, A. Veyrat, F.J. García-Breijo, J. Reig-Armiñana, and M.T. Lafuente. 2010. Epicuticular wax and morphology as related to ethylene and storage performance of 'Navelate' orange fruit. Postharvest Biol. Technol. 55(1):29-35.

Cajuste, J.F. and M.T. Lafuente. 2007. Ethyleneinduced tolerance to non-chilling peel pitting as related to phenolic metabolism and lignin content in 'Navelate' fruit. Postharvest Biol. Technol. 45(2):193-203.

Dou, H., S. Jones, and M. Ritenour. 2005. Influence of 1-MCP application and concentration on post-harvest peel disorders and incidence of decay in citrus fruit. J. Hort. Sci. Biotechnol. 80(6):786-792.

Establés-Ortiz, B., P. Romero, A.R. Ballester, L. González-Candelas, and M.T. Lafuente. 2016. Inhibiting ethylene perception with 1methylcyclopropene triggers molecular responses aimed to cope with cell toxicity and increased respiration in citrus fruits. Plant Physiol. Biochem. 103:154-166.

FAOSTAT. Food and agricultural commodities production 2014. Rome (It.): Food and Agriculture Organization of the United Nations. 18 Nov. 2016. <http://faostat3.fao.org>.

Ferrari, S., D.V. Savatin, F. Sicilia, G. Gramegna, F. Cervone, and G.D. Lorenzo. 2013. Oligogalacturonides: Plant damage-associated molecular patterns and regulators of growth and development. Front. Plant Sci. 4:49.

Gonzalez-Aguilar, G.A., L. Zacarias, M.A. PerezAmador, J. Carbonell, and M.T. Lafuente. 2000. Polyamine content and chilling susceptibility are affected by seasonal changes in temperature and by conditioning temperature in cold-stored 'Fortune' mandarin fruit. Physiol. Plant. 108(2):140-146.

Hématy, K., C. Cherk, and S. Somerville. 2009. Host-pathogen warfare at the plant cell wall. Curr. Opin. Plant Biol. 12(4):406-413.

Hernández-Mata, G., M.E. Mellado-Rojas, A. Richards-Lewis, J. López-Bucio, E. BeltranPeña, and E.L. Soriano-Bello. 2010. Plant immunity induced by oligogalacturonides alters root growth in a process involving flavonoid accumulation in Arabidopsis thaliana. J. Plant Growth Regul. 29(4):441-454.

ISO International Standard. 1995. ISO 11292: Instant coffee-Determination of free and total carbohydrate contents-Method using high performance anion-exchange chromatography.

Lado, J., M.J. Rodrigo, and L. Zacarías. 2015 Analysis of ethylene biosynthesis and perception during postharvest cold storage of Marsh and Star Ruby grapefruits. Food Sci. Technol. Intl. 21(7):537-546.

Lafuente, M.T., L. Zacarias, M.A. MartínezTéllez, M.T. Sánchez-Ballesta, and E. Dupille. 2001. Phenylalanine ammonia-lyase as related to ethylene in the development of chilling symptoms during cold storage of citrus fruits. J. Agr. Food Chem. 49(12):6020-6025.

Lafuente, M.T. and J.M. Sala. 2002. Abscisic acid levels and the influence of ethylene, humidity and storage temperature on the incidence of postharvest rindstaning of 'Navelina' orange (Citrus sinensis (L.) Osbeck) fruit. Postharvest Biol. Technol. 25(1):49-57.

Lafuente, M.T., J.M. Sala, and L. Zacarias. 2004. Active oxygen detoxifying enzymes and phenylalanine ammonia-lyase in the ethyleneinduced chilling tolerance in citrus fruit. $\mathrm{J}$. Agr. Food Chem. 52(11):3606-3611.

Lafuente, M.T. and L. Zacarías. 2006. Postharvest physiological disorders in citrus fruit. Stewart Postharvest Rev. 2(1):1-9.

Lafuente, M.T., F. Alférez, and P. Romero. 2014. Postharvest ethylene conditioning as a tool to reduce quality loss of stored mature sweet oranges. Postharvest Biol. Technol. 94:104 111.

Larskaya, I.A. and T.A. Gorshkova. 2015. Plant oligosaccharides-outsiders among elicitors? Biochemistry (Mosc.) 80(7):881-900.

Ma, Y., L. Zhou, Z. Wang, J. Chen, and G. Qu. 2016. Oligogalacturonic acids promote tomato fruit ripening through the regulation of 1 aminocyclopropane-1-carboxylic acid synthesis at the transcriptional and post-translational levels. BMC Plant Biol. 16:1-11.

Marcos, J.F., L. González-Candelas, and L. Zacarías. 2005. Involvement of ethylene biosynthesis and perception in the susceptibility of citrus fruit to Penicillium digitatum infection and the accumulation of defense-related mRNAs. J. Expt. Bot. 56 (418):2183-2193.

Martínez-Téllez, M.A. and M.T. Lafuente. 1997. Effect of high temperature conditioning on ethylene, phenylalanine ammonia-lyase, peroxidase and polyphenol oxidase activities in flavedo of chilled 'Fortune' mandarin fruit. J. Plant Physiol. 150(6):674-678.

Mathieu, Y., A. Kurkdjian, H. Xia, J. Guern, A. Koller, M.D. Spiro, M. O’Neill, P. Albersheim, and A. Darvill. 1991. Membrane response induced by oligogalacturonides in suspensioncultured tobacco cells. Plant J. 1(3):333-343.

Mulas, M. and M. Schirra. 2007. The effect of heat conditioning treatments on the postharvest quality of horticultural crops. Stewart Postharvest Rev. 3(1):1-6.
Ochoa-Villarreal, M., I. Vargas-Arispuro, M.A. Islas-Osuna, G. González-Aguilar, and M.A. Martínez-Téllez. 2011. Pectin-derived oligosaccharides increase color and anthocyanin content in Flame Seedless grapes. J. Sci. Food Agr. 91(10):1928-1930.

Ochoa-Villarreal, M., E. Aispuro-Hernández, I. Vargas-Arispuro, and M.A. Martínez-Téllez. 2012. Plant cell wall polymers: Function, structure and biological activity of their derivatives, p. 63-86. In: A. De Souza (ed.). Polymerization, InTech, Rijeka, Croatia.

Ridley, B.L., M.A. O’Neill, and D. Mohnen. 2001. Pectins: Structure, biosynthesis, and oligogalacturonide-related signaling. Phytochemistry 57(6):929-967.

Ritenour, M.A., H. Dou, and G.T. McCollum. 2003. Chilling injury of grapefruit and its control. Institute of Food and Agricultural Sciences, University of Florida. 22 Sept. 2016. <http://edis.ifas.ufl.edu/hs191>.

Sala, J.M. and M.T. Lafuente. 2000. Catalase enzyme activity is related to tolerance of mandarin fruits to chilling. Postharvest Biol. Technol. 20(1):81-89.

Sala, J.M. and M.T. Lafuente. 2004. Antioxidant enzymes activities and rind staining in 'Navelina' oranges as affected by storage relative humidity and ethylene conditioning. Postharvest Biol. Technol. 31(3):277-285.

Salvador, A., C.P. Carvalho, A. Monterde, and J.M. Martínez-Jávega. 2006. 1-MCP Effect on chilling injury development in 'Nova' and 'Ortanique' mandarins. Food Sci. Technol. Intl. 12(2): 165-170.

Sasidharan, R., L.A. Voesenek, and R. Pierik. 2011. Cell wall modifying proteins mediate plant acclimatization to biotic and abiotic stresses. Crit. Rev. Plant Sci. 30(6):548562.

Schirra, M. and M. Mulas. 1995. 'Fortune' mandarin quality following prestorage water dips and intermittent warming during cold storage. HortScience 30:560-561.

Schirra, M., M. Mulas, A. Fadda, and E. Cauli. 2004 Cold quarantine responses of blood oranges to postharvest hot water and hot air treatments. Postharvest Biol. Technol. 31(2):191200 .

Sdiri, S., P. Navarro, A. Monterde, J. Benabda, and A. Salvador. 2012. New degreening treatments to improve the quality of citrus fruit combining different periods with and without ethylene exposure. Postharvest Biol. Technol. 63(1):2532.

Stewart, I. and T.A. Wheaton. 1972. Carotenoids in citrus: Their accumulation induced by ethylene. J. Agr. Food Chem. 20(2):448-449.

Vicente, A.R., G.A. Manganaris, I.S. Minas, V. Goulas, and M.T. Lafuente. 2013. Cell wall modifications and ethylene-induced tolerance to non-chilling peel pitting in citrus fruit. Plant Sci. 210:46-52.

Zhao, J., L.C. Davis, and R. Verpoorte. 2005. Elicitor signal transduction leading to production of plant secondary metabolites. Biotechnol. Adv. 23(4):283-333. 